\title{
Environmental science and pollution research role of heavy metal concentrations and vitamin intake from food in depression: a national cross-sectional study (2009-2017)
}

\author{
Hai Duc Nguyen ${ }^{1} \cdot$ Hojin $\mathrm{Oh}^{1} \cdot$ Ngoc Hong Minh Hoang ${ }^{1} \cdot$ Won Hee Jo ${ }^{1} \cdot$ Min-Sun Kim ${ }^{1}$ (D)
}

Received: 9 June 2021 / Accepted: 11 August 2021 / Published online: 19 August 2021

(C) The Author(s), under exclusive licence to Springer-Verlag GmbH Germany, part of Springer Nature 2021

\begin{abstract}
Little is known about associations between depression and serum heavy metal levels, dietary vitamin intakes. Thus, we sought to determine the nature of these associations and to predict risks of depression using marginal effects. A data set of 16,371 individuals aged $\geq 10$ years that participated in Korea National Health and Nutrition Examination Surveys (KNHANES) conducted from 2009 to 2017 (excluding 2014 and 2015) was used to obtain information on sociodemographics, family histories, lifestyles, serum heavy metal levels, food intakes, and depression. Serum cadmium $(\mathrm{Cd})$ and lead $(\mathrm{Pb})$ levels were analyzed by graphite furnace atomic absorption spectrometry and mercury $(\mathrm{Hg})$ levels using a mercury analyzer. Daily vitamin intakes were calculated by 24 -h dietary recall. The results obtained showed that females are at higher risk of depression than males. A doubling of serum Cd was associated with a $21 \%$ increase in depression (AOR 1.21, 95\% CI: 1.07-1.37, $p=0.002$ ), whereas twofold increases in daily vitamin B1, B3 and vitamin A intakes reduced the risk of depression by $17 \%(0.83,95 \%$ CI: $0.73-0.95, p=$ $0.005), 20 \%$ (0.80, 95\% CI: $0.70-0.91, p=0.001)$, and $8 \%$ (0.92, 95\% CI: $0.85-0.99, p=0.020)$, respectively. Interactions between heavy metals, vitamin intakes, and sex did not influence the risk of depression. The result shows that increased daily dietary vitamin intake might protect the public against depression. Further studies are needed to reduce the risks posed by heavy metals and to determine more comprehensively the effects of daily dietary vitamin intake on depression.
\end{abstract}

Keywords Heavy metals $\cdot$ Depression $\cdot$ Cadmium $\cdot$ Food intakes

\section{Introduction}

The public health burden imposed by depression is massive. More than 264 million people worldwide were affected before the COVID-19 (coronavirus disease-19) pandemic (WHO 2021), and recent evidence indicates that its prevalence has increased considerably since (Czeisler et al. 2020; Ettman et al. 2020; Gao et al. 2020; Huang and Zhao 2020). South Korea has witnessed a third wave of COVID-19, and the number of individuals that experience depressive symptoms has increased in line with the number of infections (Seong et al. 2021). Depression can result in suicide, which was

Responsible Editor: Lotfi Aleya

Min-Sun Kim

minsun@scnu.ac.kr

1 Department of Pharmacy, College of Pharmacy and Research Institute of Life and Pharmaceutical Sciences, Sunchon National University, Sunchon, 57922 Jeonnam, Republic of Korea reported recently to be the second-most common cause of death among 15- to 29-year-olds (WHO 2021). Remarkedly, South Korea has the highest suicide rate among member countries of the OECD (Organization for Economic Co-operation and Development) (Lee et al. 2018). Several socioenvironmental, psychological, and physical factors, such as alcohol overconsumption, smoking, overweightedness/obesity, inactivity, and coincident chronic diseases, have been associated with the development of depression symptoms (Association AP 2013). However, increasing evidence shows that these factors do not fully explain the prevalence of depression (Lahouaoui et al. 2019), and interestingly, environmental heavy metals have also been reported to be risk factors of mental illness, especially depression (Angeli et al. 2013; Arbi et al. 2017; Poursafa et al. 2014; Valera et al. 2012).

Heavy metals have long been documented as environmental risk factors for multi-organ dysfunction. These metals are persistent environmental pollutants, which means humans are exposed to them in industrial environments and generally in food, water, and air (Ali et al. 2019). Notably, rapid 
industrialization and urbanization have increased the likelihood of heavy metal exposure (Duc et al. 2021a; Nguyen and Kim 2021; Nguyen et al. 2021; Poursafa et al. 2014). Mercury $(\mathrm{Hg})$, cadmium $(\mathrm{Cd})$, and lead $(\mathrm{Pb})$ are three of the most toxic heavy metals studied in recent years. Sources of $\mathrm{Cd}$ exposure include contaminated foods and smoking (Satarug et al. 2017). Sources of $\mathrm{Hg}$ exposure include cosmetic preparations, fossil fuels, air, contaminated waste, and food, especially contaminated seafood and fish (Çamur et al. 2016; Garí et al. 2013, Wolkin et al. 2012), and sources of $\mathrm{Pb}$ exposure include petrol, cigarette smoke, industrial processes, domestic $\mathrm{Pb}$-based paints, soil, air, water, and contaminated food (Aelion et al. 2012; Hrubá et al. 2012). Reportedly, Cd plays a vital role in the pathogenesis of depression (Orisakwe 2014), and several studies have concluded depression is associated with exposure to $\mathrm{Pb}$ and $\mathrm{Hg}$ ( $\mathrm{Ng}$ et al. 2013a; Orisakwe 2014). Although numerous researchers have attempted to evaluate the relationship between heavy metals and depression, little is known about their impacts in the Korean population (Park et al. 2016a).

Depressed patients are frequently not correctly diagnosed, and others who do not have a depressive disorder are too frequently misdiagnosed and prescribed antidepressants (WHO 2021). Recent guidelines suggest combinations of psychological and pharmacological treatments for depression management based on considerations of depression severity (Olfson et al. 2016). Growing evidence, both direct and indirect, indicates vitamin deficiency, especially B vitamin deficiency, is associated with symptoms of psychiatric disorders including depression. B vitamins play vital roles in neurochemical pathways related to noradrenergic, dopaminergic, serotonergic, and cholinergic systems and the GABA ( $\gamma$-aminobutyric acid) and glutamate neurotransmitter systems. Vitamin B deficiency can, therefore, affect several mechanisms associated with depression, such as monoamine reduction, abnormal neurotransmitter release, reduction or interruption of serotonin transmission, and abnormal dopaminergic and noradrenergic activities (Furmaga et al. 2011). Recent studies have increased understanding of the impacts of different diets on depression. For example, it has been established that daily vitamin intake and vegetable and fruit consumption reduce depression risk in the general population (Firth et al. 2020). However, little is known about the association between daily dietary vitamin intake and depression in the Korean population.

This study was undertaken to determine relations between the prevalence of depression and serum heavy metal $(\mathrm{Hg}, \mathrm{Pb}$, and $\mathrm{Cd}$ ) levels and dietary vitamin intakes in a nationally representative cohort in the hope that the knowledge gained regarding environmental predisposing factors will aid the prevention and early management of depression. irm if it is correct." -> Materials and methods

\section{Study population}

Information on the design and data collection methods used in Korea National Health and Nutrition Examination Surveys (KNHANES) has been published elsewhere (Duc et al. 2021b). In the present study, we used data from KNHANES studies conducted between 2009 and 2017. Totals of 10,533 (2009), 8958 (2010), 8518 (2011), 8058 (2012), 8018 (2013), 8150 (2016), and 8127 (2017) subjects participated in these studies. Of the 60,362 individuals that participated during 20092013 and 2016-2017, we excluded 43,509 without serum $\mathrm{Pb}, \mathrm{Cd}$, or $\mathrm{Hg}$ data and 482 without depression data. Consequently, the data of 16,371 individuals that participated in KNHANES were included in the analysis.

\section{Determination of serum $\mathrm{Pb}, \mathrm{Hg}$, and $\mathrm{Cd}$ levels}

Serum $\mathrm{Hg}, \mathrm{Pb}$, and $\mathrm{Cd}$ levels were analyzed as previously described (Nguyen and Kim 2021; Nguyen et al. 2021). Briefly, serum $\mathrm{Cd}$ and $\mathrm{Pb}$ concentrations were measured by the NEODIN Medical Institute, which is certified by the Korean Ministry of Health and Welfare. The methods used met the requirements of the German External Quality Assessment Scheme, the US CDC, and the Korea Occupational Safety and Health Administration program. $\mathrm{Pb}$ and $\mathrm{Cd}$ levels were determined by graphite furnace atomic absorption spectrometry (model AAnalyst 600, Perkin Elmer, Turku, Finland) with Zeeman background correction. Total serum $\mathrm{Hg}$ levels were determined using a direct mercury analyzer (model DMA-80 Analyzer, Bergamo, Italy). Limits of detection (LODs) $\mathrm{Pb}, \mathrm{Hg}$, and $\mathrm{Cd}$ were $0.223,0.05$, and $0.087 \mu \mathrm{g} / \mathrm{L}$, respectively. Commercial standards (Lyphochek Whole Blood Metals, Bio-Rad, CA, USA) were used as reference materials for internal quality assurance and quality control.

\section{Urinary cotinine and smoking verification}

Urinary cotinine analysis was conducted by gas chromatography and mass spectrometry (PerkinElmer Clarus 600T) on spot urine samples. The detection limit was $1.26 \mathrm{ng} / \mathrm{mL}$. Standard reference materials were used for internal quality assurance and control purposes (ClinChek, RECIPE, Munich, Germany). Urinary cotinine levels were measured using a standard G-EQUAS protocol. Subjects with a level of $\geq 50 \mathrm{ng} / \mathrm{mL}$ were defined as cotinine-verified smokers (Benowitz et al. 2002; Jung-Choi et al. 2012). 


\section{Laboratory measurements}

Blood samples were collected during mornings after an overnight fast. Serum concentrations of alanine aspartate aminotransferase (ALT), aspartate aminotransferase (AST), triglycerides, high-density lipoprotein cholesterol (HDL-C), and glucose were measured using an automatic analyzer (Hitachi 7600, Hitachi, Tokyo, Japan). Serum low-density lipoprotein cholesterol (LDL-C) levels were calculated using the Friedewald equation serum [LDL-C $=$ serum total cholesterol - serum HDL-C - (serum triglyceride)/5]. hs-CRP levels were analyzed by immunoturbidimetry using a Cobas 8000 modular analyzer (Roche, Mannheim, Germany) (Yun et al. 2021). Clinical analyses were performed by the Neodin Medical Institute, a laboratory certified by the Korean Ministry of Health and Welfare.

\section{Food intakes}

Daily food intakes were calculated using the 24-h recall method. Before assessing food intakes, all subjects were instructed to maintain their normal dietary habits. Daily dietary vitamin intakes were defined as self-assessed mean 24-h dietary intakes and calculated using Can-Pro 3.0 nutrient intake assessment software developed by the Korean Nutrition Society (Duc et al. 2021b). Total vitamin A intakes were measured by summing vitamin $\mathrm{A}$ and $\mathrm{b}$-carotene intakes and dividing by 6 (Park et al. 2015).

A semi-quantitative food frequency questionnaire (FFQ), which addressed the intakes of 63 food products, was completed by each subject. Food intake levels were categorized on a monthly, weekly, or daily basis as "never or rarely in any given month," "once a month," "once or twice a month," "once a week," "two to four times a week," "five to six times a week," "daily," "twice daily," or "three or more times daily." Three food groups (green vegetables, white vegetables, and fruit) were chosen from the 63 food items. The green vegetable group included cucumber, spinach, radish leaves, and pepper; the white vegetable group included cabbage, pumpkin, radish, sprout, Korean cabbage, carrot, and tomato; and the fruit group included tangerine, pear, persimmon, watermelon, strawberry, apple, grape, peach, banana, and citrus. Participants were classified based on vegetable and fruit consumption frequencies as low, medium, or high consumers (Duc et al. 2021a; Nguyen and Kim 2021; Park et al. 2015).

\section{Parameters}

During medical checkups, information on age, education, smoking history, and alcohol intake was collected using the standard KNHANES questionnaire. Waist circumstance $(\mathrm{cm})$ was measured at the midpoint between the bottom of the rib cage and the iliac crest at the mid-axillary line while exhaling.
Blood pressure was measured after a 5-min rest period with participants in a seated position on right arms in triplicate with 5-min intervals between measurements using a mercury sphygmomanometer, and measurements were averaged.

Physical activity was dichotomized as regular or irregular. Regular physical activity was defined as follows: (1) participation in vigorous physical activity (running, fast cycling, climbing, football, fast swimming, basketball, squash, singles tennis, rope jumping, or occupational or recreational activities involving the carrying of heavy objects), $\geq 20 \mathrm{~min}$ per session for $\geq 3$ days per week; (2) or participation in moderate physical activity (slow swimming, volleyball, doubles tennis, or occupational or recreational activity involving the carrying of light objects), $\geq 30$ min per session for $\geq 5$ days per week; or (3) walking for $\geq 30$ min per session $\geq 5$ days per week. Alcohol consumption was defined as low- or high-risk drinking (high-risk drinking was defined as $>5$ drinks per day for $\geq 1$ month) (Duc et al. 2021b).

\section{Depression}

In this study, the outcome variable depression was defined based on physician's diagnosis or the current presence or treatment for depression (Duc et al. 2021b).

\section{Statistical analysis}

The statistical analysis was performed using STATA software (version 16.0; StataCorp, TX, USA). Baseline characteristics of participants are presented as frequencies and percentages for categorical variables and as means and standard deviations or medians and interquartile ranges for continuous variables. Student's $t$-test or Mann-Whitney test was used to analyze continuous variables and the $\chi^{2}$ test was used for categorical variables.

The serum heavy metal $(\mathrm{Cd}, \mathrm{Pb}, \mathrm{Hg})$ levels and daily vitamin intake levels (vitamin B1, B2, B3, C, total vitamin A) were $\log _{2}$ transformed because their distributions were right skewed. Serum heavy metal levels and daily vitamin intakes are presented as geometric means (GMs) and $95 \%$ confidence intervals (CIs).

Associations between depression and serum heavy metal and daily vitamin intake levels were examined by logistic regression. Potential covariates were obtained from the literature, chosen based on subjective prior knowledge, or identified by univariate analysis based on a $p$-value $\leq 0.25$. Ten events per variable were carefully considered before entering these variables in the full model (Hosmer Jr et al. 2013). Logistic regression models were used to identify risk factors associated with depression. The potential factors included were sex (male, female), residential area (rural vs. urban), monthly household income $(<2000, \geq 2000$ and $<4000$, $\geq 4000$ and $<6000, \geq 6000$ ), physical activity (not regular, 
regular), occupation (managers, professional, office worker, clerical, service, sales, agricultural, forestry and fishery workers, craftsmen, elementary occupations, unemployed, and plant or machine operators or assemblers), BMI $(<18.5$, $\geq 18.5$ but $<25, \geq 25$ but $<30$, and $\geq 30 \mathrm{~kg} / \mathrm{m}^{2}$ ), high-risk drinking (yes, no), educational level ( $\leq$ middle school, high school, $\geq$ college), and cotinine-verified smoker (yes, no). Interactions between heavy metal levels and daily vitamin intakes were also evaluated. Marginal effects were then used to predict the risks of depression. Statistical tests were two sided, and $p$-values $<0.05$ were considered statistically significant.

\section{Results}

Our study included 16,371 individuals that participated in KNHANES (2009-2013, 2016-2017); the mean (SD) age of participants was 42.62 (18.12) and 8485 (51.8\%) were women. The percentage of participants with depression was $3.64 \%$ (596/16,371, 95\% CI: 3.36-3.94). Mean serum Cd, Pb, and Hg levels were 1.02 (0.67) (95\% CI: 1.01-1.03), 2.06 (1.10) (95\% CI: 2.04-2.07), and 4.06 (3.52) (95\% CI: 4.01-4.12), respectively. Daily intakes of vitamins B1, B2, B3, and C were $1.46(0.89) \mathrm{mg}(95 \% \mathrm{CI}: 1.44-1.47), 1.37(0.81)$ mg (95\% CI: 1.36-1.39), 15.99 (9.64) mg (95\% CI: 15.84-16.15), and 93.83 (97.59) mg (95\% CI: $92.23-$ 95.44), respectively.

Table 1 shows the demographic distribution of participants with depression. Those with depression were significantly more likely to be female, young adults, married, unemployed, to have a low educational level, a low-income monthly household, a healthy BMI $\left(18.5 \leq \mathrm{BMI}<25 \mathrm{~kg} / \mathrm{m}^{2}\right)$ or to be overweight $\left(25 \leq \mathrm{BMI}<30 \mathrm{~kg} / \mathrm{m}^{2}\right)$, to have a family history of CVDs or hyperlipidemia, or to be non-smokers. Cardiometabolic risk factors (total cholesterol, triglyceride, waist circumference, fasting glucose, and systolic and diastolic blood pressure), HbAlc, hemoglobin, and energy intake were significantly higher in participants with depression. Geometric mean serum Cd was significantly higher for participants with depression than for those without, but no significant difference was observed for serum $\mathrm{Pb}$ or $\mathrm{Hg}$. On the other hand, daily vitamins B1, B2, B3, C, and A and retinol intakes were significantly lower for those with depression (Table 2).

Table 3 presents adjusted odds ratios (AOR) for associations between depression status and heavy metal concentrations and daily vitamin intakes. Results showed a significant relationship between serum $\mathrm{Cd}$ levels and depression after adjustment for potential confounders. A doubling of serum $\mathrm{Cd}$ was associated with a $21 \%$ increase in depression (AOR $1.21,95 \%$ CI: $1.07-1.37, p=0.002)$. On the other hand, the risk of depression decreased as vitamin intake increased. A twofold increase in daily vitamin B1, B3, or A intake reduced the risk of depression by $17 \%(0.83,95 \%$ CI: $0.73-0.95, p=$ $0.005), 20 \%(0.80,95 \%$ CI: $0.70-0.91, p=0.001)$, and $8 \%$ $(0.92,95 \%$ CI: $0.85-0.99, p=0.020)$, respectively. Interactions between heavy metals, vitamin intakes, and sex were not found to influence the prevalence of depression.

Figure 1 shows the marginal effects of serum $\mathrm{Cd}$ and daily vitamin $\mathrm{B} 1, \mathrm{~B} 3$, or A intake on the prevalence of depression by sex after adjustment for potential confounders among all study subjects. An increase in serum $\mathrm{Cd}$ was associated with an increase in the prevalence of depression in males and females, and increases in daily vitamin B1, B3, or A intake were related to reduced risks of depression in males and females.

\section{Discussion}

Our findings provide epidemiological evidence that adds to earlier experimental results and support associations between the risk of depression and serum heavy metal levels and dietary intakes of vitamin B1, B3, or A in the Korean population. Marginal effects analysis was used to quantify the effects of heavy metals and dietary daily vitamin intakes on the prevalence of depression by sex. The study identified associations between depression and heavy metal concentrations and vitamin intakes in the Korean population. To summarize, an increase in serum $\mathrm{Cd}$ was associated with an increased risk of depression, and remarkably, the risk of depression was found to rapidly decrease when vitamin B1, B3, or total vitamin A intake increased. These findings contribute to our understanding of the effects of heavy metals and dietary vitamin intakes on the pathogenesis of depression.

Environmental toxic metal exposures have become a major public health issue over the last few decades due to their potential adverse impacts on human health (WHO 2017), and the risks associated with human exposure to heavy metals have increased globally in parallel with urbanization and industrialization (Wang et al. 2018). In the present study, we found that the risk of depression in a nationally representative cohort was associated with serum Cd levels, which were significantly higher in subjects with depression. Somewhat surprisingly, the association between serum $\mathrm{Cd}$ and depression was similar for current smokers and non-smokers, which we attribute to confounding by other compounds, like lead and cotinine, in cigarette smoke (Scinicariello and Buser 2015). Furthermore, our findings are consistent with those of previous studies (Kim et al. 2016; Orisakwe 2014). The mechanism whereby Cd-induced neurotoxicity underlies neuropsychiatric disorders is not well understood, even in animal models. However, several explanations have been proposed. First, $\mathrm{Cd}$ can cross and disrupt the blood-brain barrier, and thus, $\mathrm{Cd}$ could induce oxidative stress, and thus, mitochondrial dysfunction and even neuronal cell apoptosis in brain tissue (Chen et al. 2011; Gonçalves et al. 2010). Second, Cd can 
Table 1 Characteristics of study subjects with or without depression

\begin{tabular}{|c|c|c|c|c|}
\hline \multirow[t]{2}{*}{ Variables } & \multirow[t]{2}{*}{$N$} & \multicolumn{2}{|l|}{ Depression } & \multirow{2}{*}{$\begin{array}{l}p \text { - } \\
\text { values }\end{array}$} \\
\hline & & No & Yes & \\
\hline \multicolumn{5}{|l|}{ Demographic and social characteristics } \\
\hline $\operatorname{Sex}(\%)$ & 16,371 & & & \\
\hline Male & 7886 & $7751(49.1)$ & $135(22.7)$ & $<0.001$ \\
\hline Female & 8485 & $8024(50.9)$ & $461(77.3)$ & \\
\hline Age group (\%) & 16,371 & & & \\
\hline$\leq 29$ & 4538 & $4469(28.3)$ & $69(11.6)$ & $<0.001$ \\
\hline $30-39$ & 2755 & $2682(17.0)$ & $73(12.3)$ & \\
\hline $40-49$ & 2817 & $2714(17.2)$ & $103(17.3)$ & \\
\hline $50-59$ & 2891 & $2734(17.3)$ & $157(26.3)$ & \\
\hline $60-69$ & 2294 & $2165(13.7)$ & $129(21.6)$ & \\
\hline $70-79$ & 928 & $867(5.5)$ & $61(10.2)$ & \\
\hline$\geq 80$ & 148 & $144(1.0)$ & $4(0.7)$ & \\
\hline Marital status (\%) & 16,364 & & & \\
\hline Married & 11,395 & $10,882(69.0)$ & $513(86.1)$ & $<0.001$ \\
\hline Living alone & 4969 & $4886(31.0)$ & $83(13.9)$ & \\
\hline Residential areas $(\%)$ & 16,371 & & & \\
\hline Urban & 13,421 & $12,930(82.0)$ & $491(82.4)$ & 0.795 \\
\hline Rural & 2950 & $2845(18.0)$ & $105(17.6)$ & \\
\hline Occupation (\%) & 15,170 & & & \\
\hline Managers, professional & 2052 & $2012(13.8)$ & $40(6.8)$ & $<0.001$ \\
\hline Office worker, clerical workers & 1518 & $1487(10.2)$ & $31(5.2)$ & \\
\hline Service workers, sales workers & 2012 & $1947(13.4)$ & $65(10.9)$ & \\
\hline Agriculture, forestry and fishing workers & 757 & $728(5.0)$ & $29(4.8)$ & \\
\hline Craft, plant and machine operators and assemblers & 1638 & $1611(11.1)$ & $27(4.5)$ & \\
\hline Elementary occupations & 1259 & $1202(8.3)$ & $57(9.6)$ & \\
\hline Unemployed & 5934 & $5587(38.2)$ & $347(58.2)$ & \\
\hline Education level (\%) & 16,333 & & & \\
\hline$\leq$ Middle school & 5915 & $5639(35.8)$ & $276(46.3)$ & $<0.001$ \\
\hline High school & 5331 & $5137(32.7)$ & $194(32.6)$ & \\
\hline$\geq$ College & 5087 & $4961(31.5)$ & $126(21.1)$ & \\
\hline Monthly household income $(\%)^{*}$ & 16,264 & & & \\
\hline$<2000$ & 4327 & $4062(25.9)$ & $265(44.6)$ & $<0.001$ \\
\hline$\geq 2000$ and $<4000$ & 5320 & $5167(33.0)$ & $153(25.8)$ & \\
\hline$\geq 4000$ and $<6000$ & 3599 & $3506(22.4)$ & $93(15.6)$ & \\
\hline$\geq 6000$ & 3018 & 2935 (18.7) & $83(14.0)$ & \\
\hline BMI group (\%) & 16,339 & & & \\
\hline$<18.5$ & 1165 & $1143(7.3)$ & $22(3.6)$ & 0.004 \\
\hline$\geq 18.5$ and $<25$ & 10,197 & $9827(62.4)$ & $370(62.1)$ & \\
\hline$\geq 25$ and $<30$ & 4300 & $4122(26.2)$ & $178(29.9)$ & \\
\hline$\geq 30$ & 677 & $651(4.1)$ & $26(4.4)$ & \\
\hline Smoking status (\%) & 14,354 & & & \\
\hline Non/ex-smoker & 10,729 & $10,246(74.5)$ & $483(81.2)$ & $<0.001$ \\
\hline Current smoker & 3625 & $3513(25.5)$ & $112(18.8)$ & \\
\hline Cotinine verified smokers (\%) & 16,371 & & & \\
\hline No & 8059 & $7741(49.1)$ & $318(53.4)$ & 0.040 \\
\hline Yes & 8312 & $8034(50.9)$ & $278(46.6)$ & \\
\hline High-risk drinking status (\%) & 16,356 & & & \\
\hline
\end{tabular}


Table 1 (continued)

\begin{tabular}{|c|c|c|c|c|}
\hline \multirow[t]{2}{*}{ Variables } & \multirow[t]{2}{*}{$N$} & \multicolumn{2}{|l|}{ Depression } & \multirow{2}{*}{$\begin{array}{l}p \text { - } \\
\text { values }\end{array}$} \\
\hline & & No & Yes & \\
\hline No & 14,809 & $14,293(90.7)$ & $516(86.6)$ & 0.001 \\
\hline Yes & 1547 & $1467(9.3)$ & $80(13.4)$ & \\
\hline Physical activity (\%) & 16,371 & & & \\
\hline Not regular & 13,116 & $12,644(80.2)$ & $472(79.2)$ & 0.565 \\
\hline Regular & 3255 & $3131(19.8)$ & $124(20.8)$ & \\
\hline Family history of CVDs (\%) & 13,450 & & & \\
\hline No & 7836 & $7599(58.6)$ & $237(49.0)$ & $<0.001$ \\
\hline Yes & 5614 & $5367(41.4)$ & $247(51.0)$ & \\
\hline Family history of diabetes (\%) & 13,310 & & & \\
\hline No & 10,644 & $10,283(80.1)$ & $361(76.5)$ & 0.054 \\
\hline Yes & 2666 & $2555(19.9)$ & $111(23.5)$ & \\
\hline Family history of hyperlipidemia (\%) & 12,945 & & & \\
\hline No & 12,104 & $11,688(93.6)$ & $416(90.6)$ & 0.011 \\
\hline Yes & 841 & $798(6.4)$ & $43(9.4)$ & \\
\hline
\end{tabular}

*Thousand won

CVDs, cardiovascular diseases

adversely affect the central nervous system by triggering vascular damage via endothelial oxidative stress (Angeli et al. 2013), which several authors have concluded is a risk factor for depression (Bonaccorso et al. 2002; Förstl et al. 1991). Third, Cd-induced changes in dopamine, norepinephrine, serotonin, or thyroid hormone concentrations may be related to depression (Demartini et al. 2014; Lafuente et al. 2003; Takiguchi and Si 2006).

Several studies have reported that elevated serum levels of $\mathrm{Hg}$ and $\mathrm{Pb}$ were associated with depression, though we found no evidence of these associations (Bouchard et al. 2009; Kim et al. 2020). For example, Bouchard et al. found higher serum $\mathrm{Pb}$ levels were related to increased risks of major depression and panic disorders among young US adults (Bouchard et al. 2009), and Kyung et al. reported that higher levels of serum $\mathrm{Hg}$ were related to depression risk in Korean women, especially in those with lower fish intakes (Kim et al. 2020). Several authors have reported $\mathrm{Pb}$ can disrupt catecholaminergic systems and lead to depression and anxiety disorders (Kala and Jadhav 1995; Lasley et al. 1984). In rats, $\mathrm{Pb}$ reduced serotoninergic activity in numerous brain regions, including frontal cortex, nucleus accumbens, and brainstem (Kala and Jadhav 1995). Ng et al. found that higher total serum $\mathrm{Hg}$ was not related to an increased risk of depression among US adults (Ng et al. 2013b), and Park et al. failed to find an association between serum Hg and depression in Korean adults (Park et al. 2016b), and both of these studies concur with our findings. We believe these discrepancies were probably caused by different sample sizes, analysis methods, and population differences. Moreover, like $\mathrm{Cd}, \mathrm{Hg}$ can cross the bloodbrain barrier and induce neurotoxic symptoms (Castro-González and Méndez-Armenta 2008), and exposure to inorganic mercury, especially methylmercury, can induce neuropsychiatric symptoms by inducing oxidative stress in the central nervous system (Maximino et al. 2011).

Deficiency of any B vitamin can result in homocysteine accumulation and detrimental cellular effects, and vitamin B deficiency is known to play a role in the development of depression (Folstein et al. 2007). Vitamin B1 is important for carbohydrate metabolism and nerve function, and its deficiency can negatively impact the central nervous system (Abdou and Hazell 2015). Furthermore, the relationship between thiamine deficiency and depression among adults has been well demonstrated (Pepersack et al. 1999; Zhang et al. 2013). Our results show that vitamin B1 consumption is inversely associated with depression in the Korean population, which concurs with a previous study, in which vitamin B1 supplementation for 6 weeks reduced depressive symptoms in 80 elderly women (Smidt et al. 1991). Other studies have also reported vitamin B1 supplementation can reduce depressive symptoms and improve cognitive function among patients with geriatric depression, and in a case report, it reduced depressive symptoms in a 50-year-old man admitted to a psychiatric clinic (Bell et al. 1992; Jong and Hoek 2008). Our recent study also showed an increase in daily vitamin B1 intake was negatively associated with the prevalence of depression (Duc et al. 2021b). 
Table 2 Food intake and laboratory measurements of study subjects with or without depression

\begin{tabular}{|c|c|c|c|c|}
\hline \multirow[t]{2}{*}{ Variables } & \multirow[t]{2}{*}{$N$} & \multicolumn{2}{|l|}{ Depression } & \multirow[t]{2}{*}{$p$-value } \\
\hline & & No & Yes & \\
\hline \multicolumn{5}{|l|}{ Food intake } \\
\hline Energy intake (kcal) & 14,225 & $2042.72 \pm 7.63$ & $1691.60 \pm 32.80$ & $<0.001$ \\
\hline Vitamin B1 intake $(m g) \ddagger$ & 14,225 & $1.26(1.24-1.27)$ & $0.99(0.94-1.04)$ & $<0.001$ \\
\hline Vitamin B2 intake $(m g) \ddagger$ & 14,225 & $1.17(1.16-1.18)$ & $0.95(0.90-1.01)$ & $<0.001$ \\
\hline Vitamin B3 intake $(m g) \ddagger$ & 14,225 & $13.82(13.69-13.95)$ & $10.80(10.28-11.35)$ & $<0.001$ \\
\hline Vitamin C intake $(m g) \ddagger$ & 14,225 & $62.79(61.79-63.80)$ & $52.75(48.50-57.39)$ & 0.001 \\
\hline Total vitamin A intake $(\mathrm{mg}) \ddagger$ & 14,225 & $481.40(473.67-489.26)$ & $392.76(358.76-429.99)$ & $<0.001$ \\
\hline $\operatorname{Retinol}(\mu g) \neq$ & 14,225 & $52.45(50.95-53.99)$ & $32.29(26.96-38.67)$ & $<0.001$ \\
\hline Green vegetables $(\%) \S$ & 4246 & & & \\
\hline Low consumption & 3168 & $3039(74.4)$ & $129(80.6)$ & 0.051 \\
\hline Medium consumption & 816 & $797(19.5)$ & 19 (11.9) & \\
\hline High consumption & 262 & $250(6.1)$ & $12(7.5)$ & \\
\hline White vegetables $(\%) \S$ & 4257 & & & \\
\hline Low consumption & 3324 & $3195(78.0)$ & $129(80.6)$ & 0.311 \\
\hline Medium consumption & 716 & $689(16.8)$ & $27(16.9)$ & \\
\hline High consumption & 217 & $213(5.2)$ & $4(2.5)$ & \\
\hline Fruits (\%)§ & 4258 & & & \\
\hline Low consumption & 3580 & $3440(83.9)$ & $140(87.5)$ & 0.275 \\
\hline Medium consumption & 318 & $306(7.5)$ & $12(7.5)$ & \\
\hline High consumption & 360 & $352(8.6)$ & $8(5.0)$ & \\
\hline \multicolumn{5}{|l|}{ Laboratory measurements } \\
\hline Waist circumference $(\mathrm{cm})$ & 16,343 & $79.86 \pm 0.09$ & $81.27 \pm 0.42$ & 0.002 \\
\hline Total cholesterol $(m g / d L)$ & 16,370 & $185.80 \pm 0.30$ & $192.82 \pm 1.56$ & $<0.001$ \\
\hline LDL-C $(m g / d L)$ & 8090 & $111.97 \pm 0.37$ & $115(44-174)$ & 0.126 \\
\hline Triglyceride $(m g / d L) \dagger$ & 16,370 & $101(42-154)$ & $148.00 \pm 5.82$ & $<0.001$ \\
\hline HDL-C $(m g / d L)$ & 16,368 & $50.35 \pm 0.10$ & $50.09 \pm 0.53$ & 0.611 \\
\hline HbA1c (\%) & 12,377 & $5.71 \pm 0.01$ & $5.84 \pm 0.04$ & 0.002 \\
\hline Fasting glucose $(\mathrm{mg} / \mathrm{dL})$ & 16,368 & $97.33 \pm 0.17$ & $99.12 \pm 0.90$ & 0.048 \\
\hline hs-CRP $(m g / L)$ & 5055 & $1.22 \pm 0.03$ & $1.16 \pm 0.11$ & 0.652 \\
\hline Hemoglobin $(g / d L)$ & 16,367 & $14.14 \pm 0.01$ & $13.62 \pm 0.06$ & $<0.001$ \\
\hline Systolic blood pressure $(\mathrm{mmHg})$ & 16,358 & $116.64 \pm 0.13$ & $119.52 \pm 0.70$ & $<0.001$ \\
\hline Diastolic blood pressure $(\mathrm{mmHg})$ & 16,358 & $75.04 \pm 0.09$ & $75.93 \pm 0.41$ & 0.047 \\
\hline $\mathbf{A S T}(I U / L)$ & 16,370 & $22.00 \pm 0.12$ & $22.59 \pm 0.44$ & 0.331 \\
\hline ALT $(I U / L)$ & 16,370 & $21.39 \pm 0.16$ & $21.34 \pm 0.63$ & 0.959 \\
\hline Serum Cd $(\mu g / L) \ddagger$ & 16,371 & $0.81(0.80-0.81)$ & $1.11(1.06-1.16)$ & $<0.001$ \\
\hline Serum Pb $(\mu g / d L) \ddagger$ & 16,371 & $1.84(1.82-1.85)$ & $1.85(1.79-1.91)$ & 0.748 \\
\hline Serum Hg $(\mu g / L) \ddagger$ & 16,371 & $3.26(3.23-3.29)$ & $3.09(2.93-3.25)$ & 0.039 \\
\hline
\end{tabular}

†Median (IQR); łgeometric mean (95\% confidence interval) and $p$-value using Mann-Whitney test; §data available in 2012, 2013 , and 2016 $B M I$, body mass index $\left(\mathrm{kg} / \mathrm{m}^{2}\right) ; A S T$, aminotransferase; $A L T$, alanine aminotransferase

Vitamin B1 intake may also protect against heavy metalinduced stress. In an in vivo study conducted using SpragueDawley rats injected with $5 \mathrm{mg}$ of $\mathrm{CdCl} 2 \cdot \mathrm{H} 2 \mathrm{O} / \mathrm{kg}$, vitamin $\mathrm{B} 1$ appeared to have protective effects (Casas et al. 1995). Another study reported that vitamin B1 might be more therapeutically effective than thiol chelating agents at protecting rats from the toxic effects of $\mathrm{Cd}$ (Tandon and Prasad 2000). Dhawan et al. reported that a mixture of vitamins $\mathrm{B} 1$ and $\mathrm{C}$ increased the urinary elimination of $\mathrm{Pb}$, reduced hepatic and renal $\mathrm{Pb}$ stress, and reversed the $\mathrm{Pb}$-induced 
Table 3 Adjusted odds ratio (AOR) for the risk of depression

\begin{tabular}{|c|c|c|}
\hline Variables & $95 \% \mathrm{CI}$ & $p$-value 9 \\
\hline \multicolumn{3}{|l|}{ Heavy metals } \\
\hline $\log _{2}$ serum $C d$ & $1.21(1.07-1.37)$ & 0.002 \\
\hline \multirow[t]{2}{*}{ Sex- $\log 2$ serum $C d$} & Male- $\log _{2}$ serum $C d($ Ref) & \\
\hline & $1.25(0.95-1.65)$ & 0.118 \\
\hline $\log _{2}$ serum $\mathrm{Hg}$ & $0.95(0.85-1.08)$ & 0.438 \\
\hline \multirow[t]{2}{*}{$\mathrm{Sex}-\log _{2}$ serum $\mathrm{Hg}$} & Male- $\log _{2}$ serum Hg (Ref) & \\
\hline & $1.03(0.79-1.35)$ & 0.553 \\
\hline $\log _{2}$ serum $\mathrm{Pb}$ & $1.03(0.87-1.22)$ & 0.726 \\
\hline \multirow[t]{2}{*}{$\mathrm{Sex}-\log _{2}$ serum $\mathrm{Pb}$} & Male- $\log _{2} \operatorname{serum} C d(\operatorname{Ref})$ & \\
\hline & $1.47(1.01-2.15)$ & 0.046 \\
\hline \multicolumn{3}{|l|}{ Food intake } \\
\hline $\log _{2}$ vitamin B1 intake & $0.83(0.73-0.95)$ & 0.005 \\
\hline \multirow[t]{2}{*}{ Sex- $\log _{2}$ vitamin B1 intake } & Male- $\log _{2}$ vitamin B1 intake (Ref) & \\
\hline & $0.89(0.63-1.25)$ & 0.503 \\
\hline $\mathrm{Log}_{2}$ vitamin B2 intake & $0.93(0.93-1.05)$ & 0.250 \\
\hline \multirow[t]{2}{*}{ Sex- $\log _{2}$ vitamin $B 2$ intake } & Male- $\log _{2}$ vitamin B2 intake (Ref) & \\
\hline & $0.84(0.62-1.13)$ & 0.245 \\
\hline $\mathrm{Log}_{2}$ vitamin B3 intake & $0.80(0.70-0.91)$ & 0.001 \\
\hline \multirow[t]{2}{*}{ Sex- $\log _{2}$ vitamin B3 intake } & Male $-\log _{2}$ vitamin B3 intake (Ref) & \\
\hline & $1.08(0.79-1.48)$ & 0.611 \\
\hline $\log _{2}$ vitamin C intake & $0.83(0.96-0.100)$ & 0.055 \\
\hline \multirow[t]{2}{*}{ Sex- $\log _{2}$ vitamin C intake } & Male- $\log _{2}$ vitamin $C$ intake (Ref) & \\
\hline & $0.95(0.78-1.15)$ & 0.568 \\
\hline $\mathrm{Log}_{2}$ total vitamin A intake & $0.92(0.85-0.99)$ & 0.020 \\
\hline \multirow[t]{2}{*}{ Sex- $\log _{2}$ total vitamin A intake } & Male - $\log _{2}$ total vitamin A intake (Ref) & \\
\hline & $1.03(0.86-1.23)$ & 0.769 \\
\hline $\mathrm{Log}_{2}$ retinol intake & $0.99(0.95-1.03)$ & 0.671 \\
\hline \multirow[t]{2}{*}{ Sex- $\log _{2}$ retinol intake } & Male $-\log _{2}$ retinol intake (Ref) & \\
\hline & $1.03(0.93-1.04)$ & 0.541 \\
\hline
\end{tabular}

Adjusted for sex (male, female), residential area (rural vs. urban), household income $(<2000, \geq 2000$ but $<4000$, $\geq 4000$ but $<6000$, and $\geq 6000$ thousand won/month) physical activity (not regular, regular), occupation (managers, professional, office, clerical, service, sales, agricultural, forestry, and fishery workers, craft, plant/machine operators and assemblers, and the unemployed), BMIs were classified as $<18.5, \geq 18.5$ but $<25$, and $\geq 25$ but $<30, \geq 30$ ), high-risk drinking (yes, no), education level ( $\leq$ middle school, high school, $\geq$ college), cotinine-verified smoker (yes, no). inhibition of 5-aminolevulinic acid dehydratase ( $\delta$-ALA-D) in blood (Dhawan et al. 1988). Bratton et al. suggested vitamin B1 interacts with $\mathrm{Pb}$ in several ways to protect against tissue accumulation, thereby thwarting clinical signs and death. The authors proposed that therapeutic doses of vitamin B1 may be useful for preventing and treating animals or people exposed to high environmental levels from its toxic effects (Bratton et al. 1981). Reddy et al. theorized $\mathrm{Pb}$ may interact with the pyrimidine ring of vitamin $\mathrm{B} 1$ and cause its solubilization at physiological $\mathrm{pH}$ values, and reported that vitamin $\mathrm{B} 1$ treatment can reduce $\mathrm{Pb}$ levels in kidneys, blood, and bones (Reddy et al. 2010). Further work is required to determine whether interactions between vitamin 1 and heavy metals influence the risk of depression.
We also found dietary vitamin B3 intake was associated with a reduced risk of depression, which also agrees with previous studies (Smesny et al. 2010; Thompson and Proctor 1953). In a recent study, it was reported vitamin B3 levels were substantially lower in patients with depression than in controls (Ryan et al. 2020). It may be that vitamin B3 is transformed in vivo into nicotinamide, which has benzodiazepine-like effects on the $\gamma$-aminobutyric acid (GABA) system (Möhler et al. 1979; Tallman et al. 1980). In addition, vitamin B3 has been associated with the kynurenine pathway and interacts with brain receptors, which play important roles in the pathogenesis of depression (Mikkelsen et al. 2016; Miller et al. 2009). 

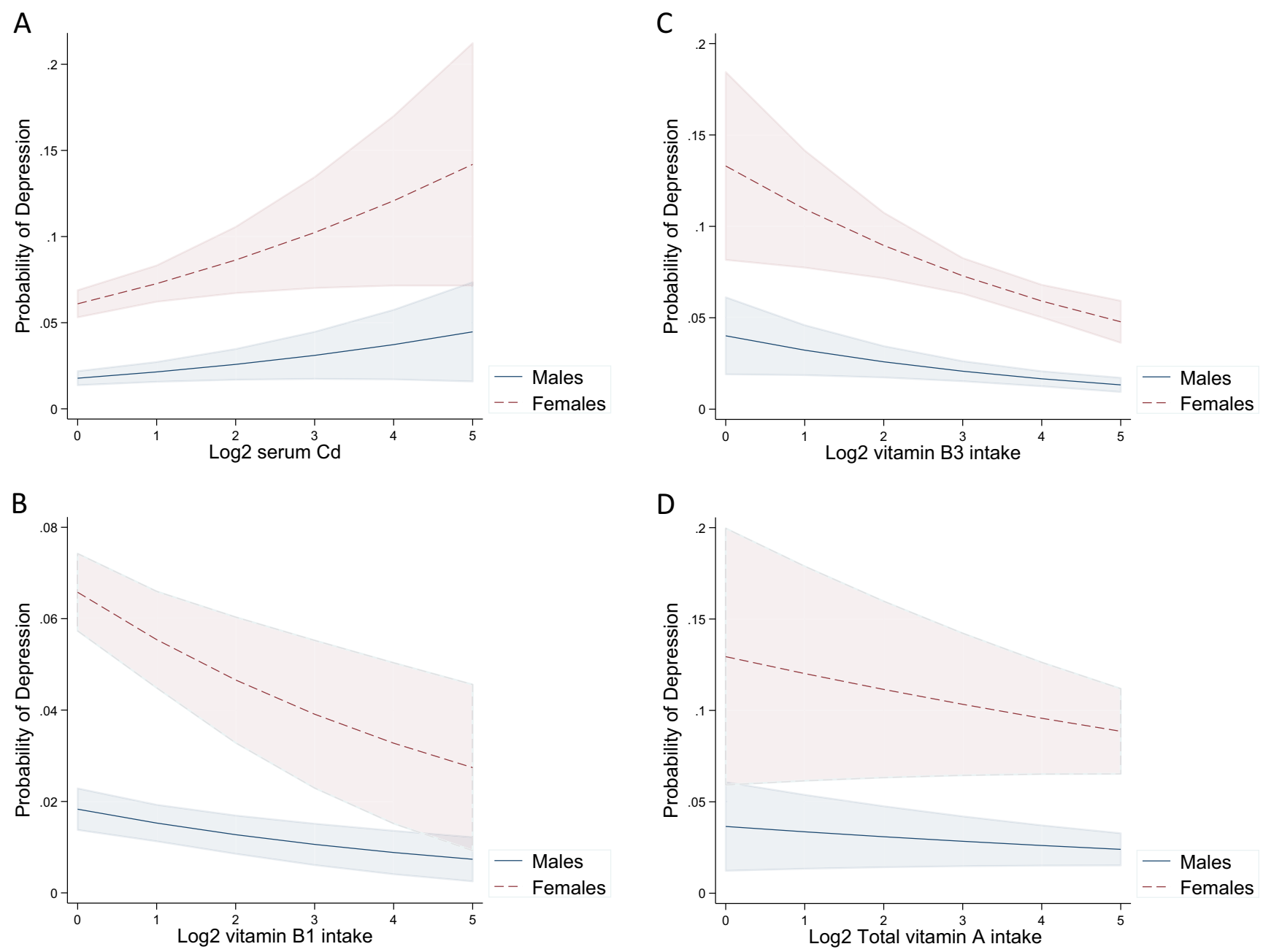

Fig. 1 Marginal effects of serum Cd (A), vitamin B1 (B), vitamin B3 (C), and total vitamin A levels (D) on depression by sex for all study subjects after adjustment for potential confounders

Exposure to heavy metals induces the formation of reactive oxygen species (ROS) (Duc et al. 2021a; Nguyen and Kim 2021), and ROS-induced oxidative stress is related to the pathogenesis of depression (Michel et al. 2012). Vitamin B3 has significant antioxidant properties (Cho et al. 2009), and thus, might protect against oxidative stress induced by heavy metals. In an in vivo study, vitamin B3 appeared to protect rat fertility from the adverse effects of $\mathrm{MeHg}$ (Frenedoso da Silva et al. 2014). Paula et al. also suggested that vitamin B3 co-administration might reverse GSH depletion and attenuate malondialdehyde and nitric oxide levels and DNA damage in rats exposed to MeHg. The authors suggested that the mechanism underlying these effects might be associated with the intrinsic antioxidant potential of vitamin B3 (Silva de Paula et al. 2016). Although data is lacking regarding relationships between vitamin B3, heavy metals, and depression, vitamin B3 supplementation is viewed as a candidate treatment for depression. Further studies are needed to assess the effectiveness of vitamin B3 in depression.
On the other hand, an increase in daily retinol intake was not associated with a decrease in the prevalence of depression, which was in line with a previous study (Nguyen et al. 2017), but we found total vitamin A intake was negatively associated with depression. This observation supports the result of a previous study, in which low serum levels of carotenoids were related to depressive symptoms and increase risk of new depressive symptoms in individuals older than 65 (Milaneschi et al. 2012). Although the mechanism whereby vitamin A affects depression has not been determined, the mechanism seems to be associated with oxidative stress and inflammation. Several studies have reported depressive patients had higher oxidative stress levels and lower antioxidant capacities than non-depressed patients (Kodydková et al. 2009; Maes et al. 2010). Furthermore, depressive mood is also strongly associated with impaired inflammatory status and antioxidant capacity, and it has been documented that depressive mood is strongly associated with impaired antioxidant defense and inflammatory status (Cumurcu et al. 2009). Notably, Bremner and Ludot reported that retinoic acid, the active form of 
vitamin A, can cause suicide and depression in some susceptible patients (Bremner et al. 2012; Ludot et al. 2015). Furthermore, associations between vitamin A and heavy metals have also been reported. Cd may impair vitamin A release, particularly from stores to serum (Sugawara and Sugawara 1978), and Sugawara found that Cd at $6.2 \mathrm{mg} / \mathrm{kg}$ considerably reduced serum levels of vitamin A for 2 weeks after final injections in rats, but had no effect on hepatic vitamin A contents (Sugawara and Sugawara 1979). Furthermore, Engström et al. concluded that an adequate vitamin A status can help minimize the negative impact of $\mathrm{Cd}$ on bone mineral density (Engström et al. 2011). Taken together, it is evident that further work is needed to improve understanding of the association between vitamin A and heavy metals.

\section{Conclusions}

To the best of our knowledge, this large-scale study is the first to report the effects of dietary vitamin intake and serum heavy metal levels on depression in a nationally representative sample of the Korean population. However, this study has several limitations. First, the cross-sectional method used in KNHANES did not allow causality to be established between depression and vitamin intakes or serum heavy metal levels. Second, the cross-sectional method used in KNHANES prevented us from accessing the vitamin effect thresholds or plateaus. Third, as no physiological markers of antioxidant status was measured during KNHANES, oxidation statuses and vitamin concentrations in plasma and tissues were not evaluated. Fourth, we investigated associations between vitamins and heavy metals in a background of depression, and thus, the impacts of relationships between macronutrients (protein, fats, carbohydrates) and heavy metals on depression need further study. Fifth, vitamin intakes were calculated using 24-h recall data, and thus, may have been under- or overestimated; though before evaluating food intakes, all participants were instructed to maintain their usual dietary habits.

Rapid industrialization and urbanization have increased exposure to heavy metals, and exposure to these metals and dietary and lifestyle changes may have increased the incidence of depression. Our findings indicate that an increase in serum $\mathrm{Cd}$ is associated with an increased risk of depression and that higher vitamin B1, B3, or A intake reduced the risk of depression in a nationally representative Korean cohort.

Eating a balanced diet every day provides the nutrients necessary to maintain health. Fruits and vegetables are sources of vitamins, and thus, balanced diets containing vegetables and fruits may reduce the risk of depression. Further studies are needed to identify the risk factors of heavy metal exposure and to determine the effects of dietary vitamin intake on depression risk.
Acknowledgments The authors are grateful to all research staff that contributed to the data collection required for this study.

Author contribution Hai Duc Nguyen: conceptualization, methodology, formal analysis, investigation, resources, data curation, writing - original draft, writing - review and editing, and visualization. Min-Sun Kim: conceptualization, methodology, formal analysis, investigation, resources, data curation, writing - original draft, writing - review and editing, visualization, supervision, and project administration. Hojin Oh: validation, investigation, writing - review and editing, and visualization. Ngoc Minh Hong Hoang: investigation and visualization. Won Hee Jo: investigation and visualization.

Funding This work was supported by National Research Foundation of Korea (NRF) grant funded by the Korea government (MEST) (grant nos. NRF2013R1A1A3008851 and 2018R1D1A1B07049610).

Data availability The datasets analyzed during the current study are available in the NHANES repository. (http://knhanes.cdc.go.kr/).

\section{Declarations}

Ethics approval and consent to participate Before examinations, all that participated in KNHANES provided written informed consent. KNHANES studies were performed by the Health and Nutrition Examination Department of the Korea Centers for Disease Control and Prevention (KCDC). This study was approved by the KNHANES inquiry commission and the Institutional Review Board of Sunchon National University. These surveys were conducted with the approval of the IRB of the KCDC (2009-01CON-03-2C, 2010-02CON-21-C, 2011-02CON-06-C, 2012-01EXP-01-2C, 2013-07CON-03-4C, 2013-12EXP-03-5C, 2015-01-02-6C, 2018-01-03-P-A). Between 2016 and 2019, KNHANES was exempt from research ethics review as stipulated by the Korean Bioethics and Safety Act.

Consent for publication Not applicable.

Competing interests The authors declare no competing interests.

\section{References}

Abdou E, Hazell AS (2015) Thiamine deficiency: an update of pathophysiologic mechanisms and future therapeutic considerations. Neurochem Res 40:353-361

Aelion CM, Davis HT, Lawson AB, Cai B, McDermott S (2012) Associations of estimated residential soil arsenic and lead concentrations and community-level environmental measures with motherchild health conditions in South Carolina. Health Place 18:774-781

Ali H, Khan E, Ilahi I (2019) Environmental chemistry and ecotoxicology of hazardous heavy metals: environmental persistence, toxicity, and bioaccumulation. Journal of chemistry 2019:1-14

Angeli JK, Pereira CAC, de Oliveira FT, Stefanon I, Padilha AS, Vassallo DV (2013) Cadmium exposure induces vascular injury due to endothelial oxidative stress: the role of local angiotensin II and COX-2. Free Radic Biol Med 65:838-848

Arbi S, Oberholzer HM, Van Rooy MJ, Venter C, Bester MJ (2017) Effects of chronic exposure to mercury and cadmium alone and in combination on the coagulation system of Sprague-Dawley rats. Ultrastruct Pathol 41:275-283

Association AP (2013): Diagnostic and statistical manual of mental disorders (DSM-5®). American Psychiatric Pub 
Bell IR, Edman JS, Morrow FD, Marby DW, Perrone G, Kayne HL, Greenwald M, Cole JO (1992) Brief Communication: vitamin Bi, B2, and Bs. J Am Coll Nutr 2:159-163

Benowitz N, Jacob P, Ahijevych K, Jarvis M, Hall S, LeHouezec J (2002) SRNT Subcommittee on Biochemical Verification. Biochemical verification of tobacco use and cessation. Nicotine Tob Res 4: 149-159

Bonaccorso S, Marino V, Biondi M, Grimaldi F, Ippoliti F, Maes M (2002) Depression induced by treatment with interferon-alpha in patients affected by hepatitis C virus. J Affect Disord 72:237-241

Bouchard MF, Bellinger DC, Weuve J, Matthews-Bellinger J, Gilman SE, Wright RO, Schwartz J, Weisskopf MG (2009) Blood lead levels and major depressive disorder, panic disorder, and generalized anxiety disorder in US young adults. Arch Gen Psychiatry 66: 1313-1319

Bratton GR, Żmudzki J, Bell MC, Warnock LG (1981) Thiamin (vitamin B1) effects on lead intoxication and deposition of lead in tissues: therapeutic potential. Toxicol Appl Pharmacol 59:164-172

Bremner JD, Shearer KD, McCaffery PJ (2012) Retinoic acid and affective disorders: the evidence for an association. The Journal of clinical psychiatry 73:37-50

Çamur D, Güler Ç, Vaizoğlu SA, Özdilek B (2016) Determining mercury levels in anchovy and in individuals with different fish consumption habits, together with their neurological effects. Toxicol Ind Health 32:1215-1223

Casas JS, Castellano EE, Couce MD, Sanchez A, Sordo J, Varela JM, Zukerman-Schpector J (1995) Vitamin B1: chemical interaction with $\mathrm{CdCl} 2$ and in vivo effects on cadmium toxicity in rats. Crystal structure of $[\mathrm{Cd}$ (thiamine $) \mathrm{Cl} 3] 2$.cntdot.2H2O, a complex containing pyrimidine and cadmium-hydroxyethyl bonds. Inorg Chem 34:2430-2437

Castro-González M, Méndez-Armenta M (2008) Heavy metals: implications associated to fish consumption. Environ Toxicol Pharmacol 26:263-271

Chen L, Xu B, Liu L, Luo Y, Zhou H, Chen W, Shen T, Han X, Kontos CD, Huang S (2011) Cadmium induction of reactive oxygen species activates the mTOR pathway, leading to neuronal cell death. Free Radic Biol Med 50:624-632

Cho KH, Kim HJ, Rodriguez-Iturbe B, Vaziri ND (2009) Niacin ameliorates oxidative stress, inflammation, proteinuria, and hypertension in rats with chronic renal failure. Am J Physiol Ren Physiol 297:F106F113

Cumurcu BE, Ozyurt H, Etikan I, Demir S, Karlidag R (2009) Total antioxidant capacity and total oxidant status in patients with major depression: impact of antidepressant treatment. Psychiatry Clin Neurosci 63:639-645

Czeisler MÉ, Lane RI, Petrosky E, Wiley JF, Christensen A, Njai R, Weaver MD, Robbins R, Facer-Childs ER, Barger LK (2020) Mental health, substance use, and suicidal ideation during the COVID-19 pandemic - United States, June 24-30, 2020. Morb Mortal Wkly Rep 69:1049-1057

Demartini B, Ranieri R, Masu A, Selle V, Scarone S, Gambini O (2014) Depressive symptoms and major depressive disorder in patients affected by subclinical hypothyroidism: a cross-sectional study. J Nerv Ment Dis 202:603-607

Dhawan M, Kachru DN, Tandon SK (1988) Influence of thiamine and ascorbic acid supplementation on the antidotal efficacy of thiol chelators in experimental lead intoxication. Arch Toxicol 62:301-304

Duc HN, Oh H, Kim MS (2021) Effects of antioxidant vitamins, curry consumption, and heavy metal levels on metabolic syndrome with comorbidities: a Korean community-based cross-sectional study. Antioxidants (Basel, Switzerland) 10(5):808

Duc HN, Oh H, Yoon IM, Kim M-S (2021b) Association between levels of thiamine intake, diabetes, cardiovascular diseases and depression in Korea: a national cross-sectional study. Journal of Nutritional Science 10:e31
Engström A, Håkansson H, Skerfving S, Bjellerup P, Lidfeldt J, Lundh T, Samsioe G, Vahter M, Åkesson A (2011) Retinol may counteract the negative effect of cadmium on bone. J Nutr 141:2198-2203

Ettman CK, Abdalla SM, Cohen GH, Sampson L, Vivier PM, Galea S (2020) Prevalence of depression symptoms in US adults before and during the COVID-19 pandemic. JAMA Netw Open 3:e2019686e2019686

Firth J, Gangwisch JE, Borisini A, Wootton RE, Mayer EA (2020) Food and mood: how do diet and nutrition affect mental wellbeing? BMJ (Clinical research ed) 369:m2382

Folstein M, Liu T, Peter I, Buel J, Arsenault L, Scott T, Qiu WW (2007) The homocysteine hypothesis of depression. Am J Psychiatr 164: $861-867$

Förstl H, Almeida OP, Owen AM, Burns A, Howard R (1991) Psychiatric, neurological and medical aspects of misidentification syndromes: a review of 260 cases. Psychol Med 21:905-910

Frenedoso da Silva R, Missassi G, dos Santos BC, Silva de Paula E, Hornos Carneiro MF, Grotto D, Barbosa Junior F, De Grava KW (2014) Phytoremediation potential of Maná-Cubiu $(<i>$ Solanum sessiliflorum $</ i>$ Dunal) for the deleterious effects of methylmercury on the reproductive system of rats. Biomed Res Int 2014: 309631

Furmaga H, Shah A, Frazer A (2011) Serotonergic and noradrenergic pathways are required for the anxiolytic-like and antidepressantlike behavioral effects of repeated vagal nerve stimulation in rats. Biol Psychiatry 70:937-945

Gao J, Zheng P, Jia Y, Chen H, Mao Y, Chen S, Wang Y, Fu H, Dai J (2020) Mental health problems and social media exposure during COVID-19 outbreak. PLoS One 15:e231924

Garí M, Grimalt JO, Torrent M, Sunyer J (2013) Influence of sociodemographic and diet determinants on the levels of mercury in preschool children from a Mediterranean island. Environ Pollut 182: 291-298

Gonçalves JF, Fiorenza AM, Spanevello RM, Mazzanti CM, Bochi GV, Antes FG, Stefanello N, Rubin MA, Dressler VL, Morsch VM (2010) N-acetylcysteine prevents memory deficits, the decrease in acetylcholinesterase activity and oxidative stress in rats exposed to cadmium. Chem Biol Interact 186:53-60

Hosmer DW Jr, Lemeshow S, Sturdivant RX (2013) Applied logistic regression, 398. John Wiley \& Sons

Hrubá F, Strömberg U, Černá M, Chen C, Harari F, Harari R, Horvat M, Koppová K, Kos A, Krsková A (2012) Blood cadmium, mercury, and lead in children: an international comparison of cities in six European countries, and China, Ecuador, and Morocco. Environ Int 41:29-34

Huang Y, Zhao N (2020) Generalized anxiety disorder, depressive symptoms and sleep quality during COVID-19 outbreak in China: a webbased cross-sectional survey. Psychiatry Res 288:112954

Jong PB, Hoek H (2008) Thiamine deficiency caused by malnutrition: a rare cause? Tijdschrift voor psychiatrie 50:611-615

Jung-Choi K-H, Khang Y-H, Cho H-J (2012) Hidden female smokers in Asia: a comparison of self-reported with cotinine-verified smoking prevalence rates in representative national data from an Asian population. Tob Control 21:536-542

Kala SV, Jadhav AL (1995) Region-specific alterations in dopamine and serotonin metabolism in brains of rats exposed to low levels of lead. Neurotoxicology 16:297-308

Kim K-N, Lee M-R, Choi Y-H, Lee B-E, Hong Y-C (2016) Associations of blood cadmium levels with depression and lower handgrip strength in a community-dwelling elderly population: a repeatedmeasures panel study. Journals of Gerontology Series A: Biomedical Sciences and Medical Sciences 71:1525-1530

Kim KW, Sreeja SR, Kwon M, Yu YL, Kim MK (2020) Association of blood mercury level with the risk of depression according to fish intake level in the general Korean population: findings from the 
Korean National Health and Nutrition Examination Survey (KNHANES) 2008-2013. Nutrients 12:189

Kodydková J, Vávrová L, Zeman M, Jirák R, Macásek J, Stanková B, Tvrzická E, Zák A (2009) Antioxidative enzymes and increased oxidative stress in depressive women. Clin Biochem 42:1368-1374

Lafuente A, Gonzalez-Carracedo A, Romero A, Esquifino A (2003) Effect of cadmium on 24-h variations in hypothalamic dopamine and serotonin metabolism in adult male rats. Exp Brain Res 149: 200-206

Lahouaoui H, Aimrane A, Khamsi Y, Zouhairi N, Benammi H, El Hidan MA, Draoui A, Alahyane H, Bouazza A (2019) Depression and anxiety emerging from heavy metals: what relationship?, Handbook of research on global environmental changes and human health. IGI Global, pp 305-321

Lasley SM, Greenland RD, Minnema DJ, Michaelson IA (1984) Influence of chronic inorganic lead exposure on regional dopamine and 5-hydroxytryptamine turnover in rat brain. Neurochem Res 9: $1675-1688$

Lee S-U, Park J-I, Lee S, Oh I-H, Choi J-M, Oh C-M (2018) Changing trends in suicide rates in South Korea from 1993 to 2016: a descriptive study. BMJ Open 8:e023144

Ludot M, Mouchabac S, Ferreri F (2015) Inter-relationships between isotretinoin treatment and psychiatric disorders: depression, bipolar disorder, anxiety, psychosis and suicide risks. World journal of psychiatry 5:222-227

Maes M, Mihaylova I, Kubera M, Uytterhoeven M, Vrydags N, Bosmans E (2010) Increased plasma peroxides and serum oxidized low density lipoprotein antibodies in major depression: markers that further explain the higher incidence of neurodegeneration and coronary artery disease. J Affect Disord 125:287-294

Maximino C, Araujo J, Leão LKR, Grisolia ABA, Oliveira KRM, Lima MG, Batista EJO, Crespo-López ME, Gouveia A Jr, Herculano AM (2011) Possible role of serotoninergic system in the neurobehavioral impairment induced by acute methylmercury exposure in zebrafish (Danio rerio). Neurotoxicol Teratol 33:727-734

Michel TM, Pülschen D, Thome J (2012) The role of oxidative stress in depressive disorders. Curr Pharm Des 18:5890-5899

Mikkelsen K, Stojanovska L, Apostolopoulos V (2016) The effects of vitamin B in depression. Curr Med Chem 23:4317-4337

Milaneschi Y, Bandinelli S, Penninx BW, Corsi AM, Lauretani F, Vazzana R, Semba RD, Guralnik JM, Ferrucci L (2012) The relationship between plasma carotenoids and depressive symptoms in older persons. The world journal of biological psychiatry : the official journal of the World Federation of Societies of Biological Psychiatry 13:588-598

Miller CL, Murakami P, Ruczinski I, Ross RG, Sinkus M, Sullivan B, Leonard S (2009) Two complex genotypes relevant to the kynurenine pathway and melanotropin function show association with schizophrenia and bipolar disorder. Schizophr Res 113:259267

Möhler H, Polc P, Cumin R, Pieri L, Kettler R (1979) Nicotinamide is a brain constituent with benzodiazepine-like actions. Nature 278:563565

Ng THH, Mossey JM, Lee BK (2013a) Total blood mercury levels and depression among adults in the United States: National Health and Nutrition Examination Survey 2005-2008. PLoS One 8:e79339

Ng THH, Mossey JM, Lee BK (2013b) Total blood mercury levels and depression among adults in the United States: National Health and Nutrition Examination Survey 2005-2008. PLoS One 8:e79339e79339

Nguyen HD, Kim M-S (2021) Effects of heavy metal, vitamin, and curry consumption on metabolic syndrome during menopause: a Korean community-based cross-sectional study. J Menopause 28:1

Nguyen TTT, Tsujiguchi H, Kambayashi Y, Hara A, Miyagi S, Yamada Y, Nakamura H, Shimizu Y, Hori D, Suzuki F, Hayashi K, Nakamura H (2017) Relationship between vitamin intake and depressive symptoms in elderly Japanese individuals: differences with gender and body mass index. Nutrients 9(12):1319

Nguyen HD, Oh H, Hoang NHM, Kim M-S (2021) Association between heavy metals, high-sensitivity C-reaction protein and 10-year risk of cardiovascular diseases among adult Korean population. Sci Rep 11: 14664

Olfson M, Blanco C, Marcus SC (2016) Treatment of adult depression in the United States. JAMA Intern Med 176:1482-1491

Orisakwe OE (2014) The role of lead and cadmium in psychiatry. N Am J Med Sci 6:370

Park S, Ham J-O, Lee B-K (2015) Effects of total vitamin A, vitamin C, and fruit intake on risk for metabolic syndrome in Korean women and men. Nutrition 31:111-118

Park H-G, Kim S-Y, Choi S-H, Seo J-S, Lim K-Y (2016a) Total blood mercury levels and depression among adults in Korea: Korea National Health and Nutrition Examination Survey 2010? 2013. Korean Journal of Family Practice 6:70-78

Park H-G, Kim S-Y, Choi S-H, Seo J-S, Lim K-Y (2016b) Total blood mercury levels and depression among adults in Korea: Korea National Health and Nutrition Examination Survey 2010?2013. KJFP 6:70-78

Pepersack T, Garbusinski J, Robberecht J, Beyer I, Willems D, Fuss M (1999) Clinical relevance of thiamine status amongst hospitalized elderly patients. Gerontology 45:96-101

Poursafa P, Ataee E, Motlagh ME, Ardalan G, Tajadini MH, Yazdi M, Kelishadi R (2014) Association of serum lead and mercury level with cardiometabolic risk factors and liver enzymes in a nationally representative sample of adolescents: the CASPIAN-III study. Environ Sci Pollut Res 21:13496-13502

Reddy SY, Pullakhandam R, Dinesh Kumar B (2010) Thiamine reduces tissue lead levels in rats: mechanism of interaction. Biometals : an international journal on the role of metal ions in biology, biochemistry, and medicine 23:247-253

Ryan KM, Allers KA, Harkin A, McLoughlin DM (2020) Blood plasma $\mathrm{B}$ vitamins in depression and the therapeutic response to electroconvulsive therapy. Brain Behav Immun-Health 4:100063

Satarug S, Vesey DA, Gobe GC (2017) Current health risk assessment practice for dietary cadmium: data from different countries. Food Chem Toxicol 106:430-445

Scinicariello F, Buser MC (2015) Blood cadmium and depressive symptoms in young adults (20-39 years). Psychol Med 45:807-815

Seong H, Hyun HJ, Yun JG, Noh JY, Cheong HJ, Kim WJ, Song JY (2021) Comparison of the second and third waves of the COVID-19 pandemic in South Korea: importance of early public health intervention. Int J Infect Dis 104:742-745

Silva de Paula E, Carneiro MF, Grotto D, Hernandes LC, Antunes LM, Barbosa F Jr (2016) Protective effects of niacin against methylmercury-induced genotoxicity and alterations in antioxidant status in rats. Journal of toxicology and environmental health. Part A 79:174-183

Smesny S, Baur K, Rudolph N, Nenadic I, Sauer H (2010) Alterations of niacin skin sensitivity in recurrent unipolar depressive disorder. J Affect Disord 124:335-340

Smidt LJ, Cremin FM, Grivetti LE, Clifford AJ (1991) Influence of thiamin supplementation on the health and general well-being of an elderly Irish population with marginal thiamin deficiency. J Gerontol 46:M16-M22

Sugawara C, Sugawara N (1978) The effect of cadmium on vitamin A metabolism. Toxicol Appl Pharmacol 46:19-27

Sugawara C, Sugawara N (1979) The effect of heavy metals on vitamin A metabolism. Toxicol Lett 3:215-218

Takiguchi M, Si Y (2006) New aspects of cadmium as endocrine disruptor. Environmental sciences: an international journal of environmental physiology and toxicology 13:107-116 
Tallman JF, Paul SM, Skolnick P, Gallager DW (1980) Receptors for the age of anxiety: pharmacology of the benzodiazepines. Science 207: 274-281

Tandon SK, Prasad S (2000) Effect of thiamine on the cadmiumchelating capacity of thiol compounds. Hum Exp Toxicol 19:523528

Thompson L, Proctor RC (1953) Depressive and anxiety reactions treated with nicotinic acid and phenobarbital. N C Med J 14:420

Valera B, Muckle G, Poirier P, Jacobson SW, Jacobson JL, Dewailly E (2012) Cardiac autonomic activity and blood pressure among Inuit children exposed to mercury. Neurotoxicology 33:1067-1074

Wang M, Liu R, Chen W, Peng C, Markert B (2018) Effects of urbanization on heavy metal accumulation in surface soils, Beijing. J Environ Sci 64:328-334

World Health Organization (2021) Depression www.whoint/en/newsroom/fact-sheets/detail/depression. Accessed 12 Jan 2020
World Health Organization (2017) Preventing noncommunicable diseases (NCDs) by reducing environmental risk factors. World Health Organization (WHO/FWC/EPE/17.1), Geneva

Wolkin A, Hunt D, Martin C, Caldwell KL, McGeehin MA (2012) Blood mercury levels among fish consumers residing in areas with high environmental burden. Chemosphere 86:967-971

Yun S, Nguyen Duc H, Park JS, Oh C, Kim MS (2021) The association between metabolic syndrome and iron status in pre-and postmenopausal women: KNHANES in 2012. Br J Nutr:1-23

Zhang G, Ding H, Chen H, Ye X, Li H, Lin X, Ke Z (2013) Thiamine nutritional status and depressive symptoms are inversely associated among older Chinese adults. J Nutr 143:53-58

Publisher's note Springer Nature remains neutral with regard to jurisdictional claims in published maps and institutional affiliations. 